\title{
A Nanomesoporous Catalyst from Modified Red Mud and Its Application for Methane Decomposition to Hydrogen Production
}

\author{
Xiaoke Fang, ${ }^{1}$ Quanrun Liu, ${ }^{1}$ Peng Li, ${ }^{1}$ Haipeng Li, ${ }^{1}$ Fenghai Li, ${ }^{2}$ and Guangxu Huang ${ }^{1}$ \\ ${ }^{1}$ School of Materials Science and Engineering, Henan Polytechnic University, Jiaozuo 454000, China \\ ${ }^{2}$ Department of Chemistry and Engineering, Heze University, Heze 274000, China \\ Correspondence should be addressed to Quanrun Liu; qrliu@163.com
}

Received 10 December 2015; Revised 7 March 2016; Accepted 29 March 2016

Academic Editor: Saji T. Kochuveedu

Copyright ( $\odot 2016$ Xiaoke Fang et al. This is an open access article distributed under the Creative Commons Attribution License, which permits unrestricted use, distribution, and reproduction in any medium, provided the original work is properly cited.

A type of nanomesoporous modified red mud (MRM) catalyst was prepared and utilized for catalytic methane decomposition (CMD) to produce hydrogen. The modification process significantly simplified the mineral composition of the red mud (RM); in the meantime, the physical and chemical structure of RM was changed. TEM images suggested that MRM was a kind of nanomesoporous material assembled by a number of uniformly nanoscale particles, BET results showed that the pore size distributions of MRM were ranged from 3 to $12 \mathrm{~nm}$, and the specific surface area and total pore volumes of red mud improved from $8.00 \mathrm{~m}^{2} / \mathrm{g}$ and $0.08 \mathrm{~cm}^{3} / \mathrm{g}$ to $190.61 \mathrm{~m}^{2} / \mathrm{g}$ and $0.39 \mathrm{~cm}^{3} / \mathrm{g}$, respectively. The catalytic performance of the catalysts has been tested at $800^{\circ} \mathrm{C}$; the results showed that MRM exhibited much higher activity and stability than RM for CMD.

\section{Introduction}

Hydrogen has been recognized as a clean and environmentally friendly energy and attracted widespread attention [1]. The conventional hydrogen production methods such as steam methane reformation $[2,3]$ and partial oxidation of methane $[4,5]$ will generate the by-products $\mathrm{CO}_{2}$, which needs further to be separated and significantly contributes to global warming. Since only hydrogen and carbon are formed in catalytic methane decomposition (CMD) process, CMD has been regarded [6] as one of the most promising methods to prepare hydrogen. Transition metals, such as Fe [7-9], Co [10], and Ni [11-13], have been widely used as catalyst for CMD due to their high activity and relatively low reaction temperature. The catalyst supports will also affect the dispersion of active metals and the catalytic performances of the metal catalysts, generally $\mathrm{SiO}_{2}, \mathrm{Al}_{2} \mathrm{O}_{3}, \mathrm{MgO}$, and some carbon materials have been used as the supports [14-17] in these catalyst systems.

Red mud (RM), a harmful by-product of the aluminum processing industry, has been classified as hazardous waste because of its caustic/alkaline nature [18]. Red mud mainly contains aluminum, iron, silicon, titanium oxides, and hydroxides, meanwhile, iron is one of the most wellknown active components for CMD, the aluminum and silicon oxides are recognized as superior catalyst support, and these characteristics made red mud possess the potential value for catalytic application [19]. Due to its low cost, high poisoning, and sintering resistance, red mud has been studied as catalyst for a variety of reactions, such as hydrogenation [20], hydrodechlorination [21], exhaust gas clean-up [22], and catalytic combustion of methane [23]. However, few literatures reported red mud use as catalyst for CMD. Balakrishnan et al. [24] directly utilized three red mud samples for CMD, but not all of the samples showed fine performance and stability; the most effective sample showed the highest activity attributed to the highest proportion of iron, but the active time just lasted 140 minutes. Kim et al. [25] studied the performance of red mud-based catalysts for the complete oxidation of volatile organic compounds, which showed that the modified red mud exhibits much higher activity than RM. Therefore, we speculated that the poor textural properties may greatly limit the catalytic performance of red mud. 
TABLE 1: The XRF analysis of dry RM and MRM.

\begin{tabular}{lcccccrr}
\hline \multirow{2}{*}{ Samples } & \multicolumn{3}{c}{ Main compositions (\%) } & & \\
& $\mathrm{Al}_{2} \mathrm{O}_{3}$ & $\mathrm{SiO}_{2}$ & $\mathrm{Fe}_{2} \mathrm{O}_{3}$ & $\mathrm{TiO}_{2}$ & $\mathrm{CaO}$ & $\mathrm{MgO}_{2} \mathrm{O}$ \\
\hline Dry RM & 25.95 & 18.35 & 16.10 & 4.77 & 18.19 & 2.49 & 4.33 \\
MRM & 32.18 & 23.25 & 21.98 & 6.43 & 2.23 & 2.87 \\
\hline
\end{tabular}

In this work, we utilized red mud to prepare a type of catalyst that applies to methane decomposition for hydrogen production. Our purpose is restructuring the mineral composition and modifying the textural properties of red mud, so as to improve the activity and/or stability for CMD.

\section{Experimental}

2.1. Modification of Red Mud. The red mud sample was provided by Henan Zhongmei Aluminum Corporation, China. The sample was dried at $105^{\circ} \mathrm{C}$ for $2 \mathrm{~h}$, then ground, and sieved to a size of $<75 \mu \mathrm{m}$.

The modified red mud (MRM) was prepared by the typical sol-gel method. $10 \mathrm{~g}$ red mud was dissolved in $500 \mathrm{~mL} 1 \mathrm{M}$ $\mathrm{HCl}$ solution under strring for $2 \mathrm{~h}$ at $60^{\circ} \mathrm{C}$; then the resulting solution was precipitated by adding aqueous ammonia until $\mathrm{pH}$ reached 8 . The obtained samples were filtered, washed by deionized water and anhydrous ethanol several times, dried at $105^{\circ} \mathrm{C}$, then calcined at $600^{\circ} \mathrm{C}$ for $2 \mathrm{~h}$ (the main chemical composition of RM and MRM is showed in Table 1), and finally sieved to a size of $<75 \mu \mathrm{m}$.

2.2. Catalytic Methane Decomposition. The reaction of catalytic methane decomposition took place in a vertical stainless steel fixed-bed reactor $(8 \mathrm{~mm}$ i.d.). About $0.5 \mathrm{~g}$ catalyst was placed into the center of the reactor, heated to the reaction temperature under the $\mathrm{N}_{2}$ atmosphere; $\mathrm{N}_{2}$ flow rate was $30 \mathrm{~mL} / \mathrm{min}$. Then the pure $\mathrm{CH}_{4}$ (99.99 vol.\%) instead of $\mathrm{N}_{2}$ was fed into the reactor with a total volumetric hourly space velocity (VHSV) of $4.8 \mathrm{~L} /(\mathrm{h} \cdot \mathrm{gcat})$. The gas products were analyzed by gas analyzers, adopting the advanced nondispersive infrared (NDIR) technology and thermal conductivity detector (TED) technology to measure the volume percentage of products $\left(\mathrm{CO}, \mathrm{CO}_{2}, \mathrm{O}_{2}, \mathrm{CH}_{4}, \mathrm{H}_{2}\right.$, and $\left.\mathrm{C}_{n} \mathrm{H}_{m}\right)$. The conversion of methane was calculated from the following expression [26]:

$$
x_{\mathrm{CH}_{4}}=\frac{\% \mathrm{H}_{2}}{200-\% \mathrm{H}_{2}} \text {. }
$$

2.3. Characterization. X-ray diffraction (XRD) analysis was performed on a Bruker-AXS D8 Advance diffractometer, with $\mathrm{Cu} \mathrm{K} \alpha$ radiation at $40 \mathrm{kV}$ and $25 \mathrm{~mA}$ in a scanning range of $10-90^{\circ}(2 \theta)$, with a step size of $0.2^{\circ}$ and a counting rate of $2 \mathrm{~s}$ per step. Energy dispersive X-ray fluorescence (EDXRF) analysis was conducted on Magix-PW2403 energy dispersive $\mathrm{X}$-ray fluorescence analyzer. $\mathrm{N}_{2}$ adsorption/desorption isotherms were obtained on the Quantachrome AsiQM0000-3 sorption analyzer; before carrying out the measurement, each sample was outgassed at $180^{\circ} \mathrm{C}$ for $6 \mathrm{~h}$. Thermogravimetrydifferential thermal gravity (TG-DTG) analysis was done on a NETZSCH STA449C Simultaneous Thermal Analyzer, the temperature range from room temperature to $800^{\circ} \mathrm{C}$. Scanning electron microscopy (SEM) was conducted on FEI Quanta-250 PEG, applied to record the morphology of the samples before and after CMD reaction. Transmission electron microscopy (TEM) analysis was performed on a JEOL JEM-2100 microscope, operating at $200 \mathrm{kV}$. The samples were dispersed in ethanol and treated with ultrasound for $5 \mathrm{~min}$ and then deposited on a copper grid coated with preformed holey carbon film.

\section{Results and Discussion}

3.1. XRD and XRF Analysis. Figure 1 shows the XRD patterns of catalysts (dry RM and MRM) before and after catalytic methane decomposition (CMD); Table 1 shows the main chemical composition (detected by EDXRF) of dry RM and MRM. From the pattern of dry RM, the characteristic diffraction peaks due to hydrogarnet, cancrinite, calcite, and calcium titanium oxide can be observed obviously; after modification process, those peaks can not be detected in the pattern of MRM, indicating that these species were decomposed into another species (such as $\mathrm{Al}_{2} \mathrm{O}_{3}, \mathrm{SiO}_{2}$, and $\mathrm{TiO}_{2}$ ) during modification process. The other contents in dry RM such as iron oxide hydroxide $(\mathrm{FeOOH})$ and bayerite $\left(\mathrm{Al}(\mathrm{OH})_{3}\right)$ were transformed into $\mathrm{Fe}_{2} \mathrm{O}_{3}$ and $\mathrm{Al}_{2} \mathrm{O}_{3}$ during modification, respectively. As Table 1 shows, the contents of $\mathrm{CaO}$ and $\mathrm{Na}_{2} \mathrm{O}$ in MRM are much lower than those in dry RM, suggesting that most of $\mathrm{Na}$ and $\mathrm{Ca}$ have been removed during modification process, and the contents of other compositions except $\mathrm{CaO}$ and $\mathrm{Na}_{2} \mathrm{O}$ are higher than that of dry RM.

From the XRD patterns of MRM after CMD, we can observe that the characteristic peaks are attributed to the species of cementite [27] $\left(\mathrm{Fe}_{3} \mathrm{C}\right)$ with $2 \theta$ being $26.413^{\circ}, 37.633^{\circ}$, $42.893^{\circ}, 43.763^{\circ}, 44.575^{\circ}, 45.884^{\circ}$, and $49.131^{\circ}$, iron $\left(44.669^{\circ}\right)$, and graphitic carbon $\left(26.381^{\circ}, 54.542^{\circ}\right)$, and the peak ascribed to $\mathrm{Fe}_{2} \mathrm{O}_{3}$ species disappeared, which suggests that almost all the $\mathrm{Fe}_{2} \mathrm{O}_{3}$ species in MRM have been reduced into Fe during $\mathrm{CMD}$; at the same time, the CMD reaction accompanied the carbon deposition and formation of cementite. An interesting phenomenon that one should pay attention to is that the diffraction peaks due to $\mathrm{Fe}_{2} \mathrm{O}_{3}$ species $\left(33.152^{\circ}, 43.518^{\circ}\right)$ still can be detected in the pattern of dry RM after CMD, which indicates that part of the $\mathrm{Fe}_{2} \mathrm{O}_{3}$ species in dry $\mathrm{RM}$ probably has been covered by the other compositions, resulting in the fact that this part of Fe species has no activity for CMD. Moreover, the peak intensities with $2 \theta$ being $43.763^{\circ}\left(\mathrm{Fe}_{3} \mathrm{C}\right)$ and $44.669^{\circ}(\mathrm{Fe})$ in the XRD patterns of MRM after CMD are much higher than those of dry RM after CMD; this behavior indicates that far more $\mathrm{Fe}$ and $\mathrm{Fe}_{3} \mathrm{C}$ species were 


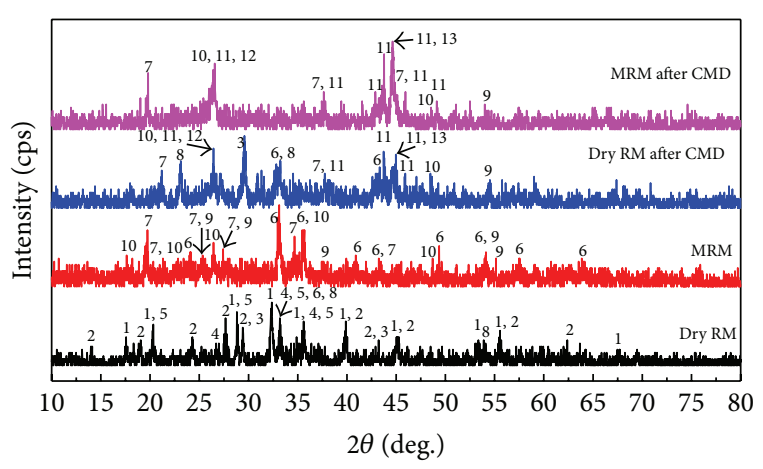

FIgURE 1: The XRD patterns of fresh and used catalysts. 1, hydrogarnet $\left(3 \mathrm{CaO} \cdot \mathrm{Al}_{2} \mathrm{O}_{3} \cdot \mathrm{SiO}_{2} \cdot 4 \mathrm{H}_{2} \mathrm{O}\right) ; 2$, cancrinite $\left(\mathrm{Na}_{6} \mathrm{CaAl}_{6} \mathrm{Si}_{6}\left(\mathrm{CO}_{3}\right) \mathrm{O}_{24} \cdot 2 \mathrm{H}_{2} \mathrm{O}\right) ; 3$, calcite $\left(\mathrm{CaCO}_{3}\right) ; 4$, iron oxide hydroxide $(\mathrm{FeOOH}) ; 5$, bayerite $\left(\mathrm{Al}(\mathrm{OH})_{3}\right) ; 6$, hematite $\left(\mathrm{Fe}_{2} \mathrm{O}_{3}\right) ; 7$, aluminum oxide $\left(\mathrm{Al}_{2} \mathrm{O}_{3}\right) ; 8$, calcium titanium oxide $\left(\mathrm{CaTiO}_{3}\right) ; 9$, titanium oxide $\left(\mathrm{TiO}_{2}\right) ; 10$, silicon oxide $\left(\mathrm{SiO}_{2}\right) ; 11$, cementite $\left(\mathrm{Fe}_{3} \mathrm{C}\right)$; 12 , graphitic carbon $(\mathrm{C})$; and 13 , iron $(\mathrm{Fe})$.

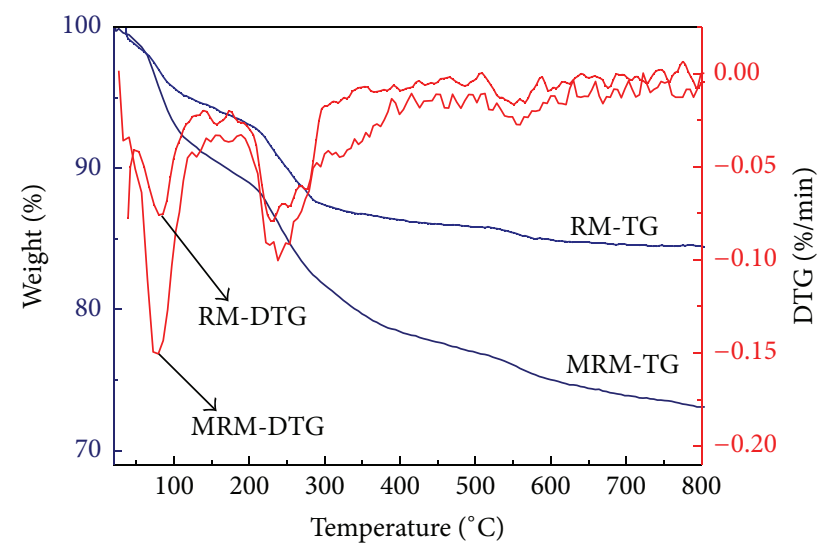

FIGURE 2: The TG-DTG curves of dry RM and MRM.

generated in MRM after CMD than those of dry RM after CMD. Therefore, much larger amount of active Fe species was generated in MRM compared to that of dry RM during CMD; this behavior should lead to higher activity of MRM than that of dry RM for CMD.

3.2. TG-DTG Analysis. Figure 2 shows the thermogravimetry (TG) and derivative thermogravimetry (DTG) curves of dry RM and uncalcined MRM precursor. The total weight loss of RM was $15.55 \%$ of the total weight from 35 to $800^{\circ} \mathrm{C}$, and the TG curve showed three weight loss steps. The first weight loss (5.21\%) step occurred in the temperature range from 35 to $129^{\circ} \mathrm{C}$, attributed to the evaporation of physically adsorbed water; the second step showed a rapid weight loss $(6.82 \%)$ between 129 and $281^{\circ} \mathrm{C}$ which was ascribed to the removal of crystal water, partial decomposition of hydroxides, such as gibbsite decomposed into boehmite [28], and transformation of goethite to hematite [29]; the third weight loss $(3.52 \%)$ step occurred in the temperature range from 281 to $800^{\circ} \mathrm{C}$, which may be due to the decomposition of carbonate [30] and remaining hydroxides. The TG curve of the uncalcined MRM catalyst precursor showed three weight loss steps that were similar to those of RM, exhibiting that continuous weight loss was approximately $26.92 \%$ of the total weight from 22 to $800^{\circ} \mathrm{C}$. The first weight loss of $8.52 \%$ from 22 to $130^{\circ} \mathrm{C}$ was mainly ascribed to the physically adsorbed water; the second weight loss of $12.29 \%$ from 130 to $364^{\circ} \mathrm{C}$ may be due to gibbsite and Fe hydroxide (formed in the homogeneous precipitation process during catalyst preparation) decomposed into $\gamma$ $\mathrm{Al}_{2} \mathrm{O}_{3}$ [31] and hematite, respectively; the third weight loss of $6.11 \%$ in the temperature range from 364 to $800^{\circ} \mathrm{C}$ was attributed to decomposition of the remaining hydroxides. The uncalcined MRM catalyst precursor exhibited a greater total weight loss than RM, which indicated that much higher hydroxide content in uncalcined MRM precursor than in RM, which should be attributed to the hydrogarnet and cancrinite in $\mathrm{RM}$ that have been dissolved by $\mathrm{HCl}$, and then the aluminum ion transformed into aluminum hydroxide during the precipitation process. The purpose of the calcining process in catalyst pretreatment is to transform the hydroxides into metal-oxides and improve the pore structure of the catalyst; however, high temperature will cause the pore structure sintering and lead to the surface areas decreasing [32]. Therefore, based on the above analysis, the calcining temperature chosen in this study was $600^{\circ} \mathrm{C}$. To investigate the morphology and textual properties of the two samples (dry RM and MRM), transmission electron microscopy (TEM) and nitrogen-adsorption-desorption were carried out in our following work.

3.3. Morphology and Textural Properties of Catalysts. Figures $3(\mathrm{a})$ and 3(b) show the TEM images of dry RM and MRM, respectively. From Figure 3(a), we can observe a number of particles with different sizes and forms; the sizes of some large particles are larger than $100 \mathrm{~nm}$. After modification, in Figure 3(b), the particles of MRM change into a number of uniformly nanoscale particles that are much smaller than the original particles in RM; meanwhile, MRM shows an abundant wormhole-like pore structure. This behavior should indicate that the modification process greatly affects the pore structure of MRM, which may be in favor of improving the catalytic performance of MRM for CMD. Figures 3(c) and 3(d) show the SEM images of dry RM and MRM, respectively. It can be observed that the large particles of dry RM with the wrapped and embedded status were transformed into small particles of MRM; this phenomenon is consistent with the results that TEM images showed above. Figures $3(\mathrm{e})$ and $3(\mathrm{f})$ show the EDX-map (Fe distribution) of dry RM and MRM, respectively. By comparing Figures 3(e) and 3(f), it is obviously found that the content of Fe distributed on the external structure of MRM is much higher than that of dry RM. This interesting phenomenon may indicate that part of the Fe species in dry RM (which have been covered by other compositions) turned exposed; attributes to the modified process changed the structure of dry RM.

Figure 4 shows the $\mathrm{N}_{2}$-adsorption-desorption isotherms (a) and the corresponding pore size distribution curves (b) of the two samples. The isotherm of dry RM can be classified as classical type I (according to the IUPAC), and there is no apparent peak in the pore size distribution 


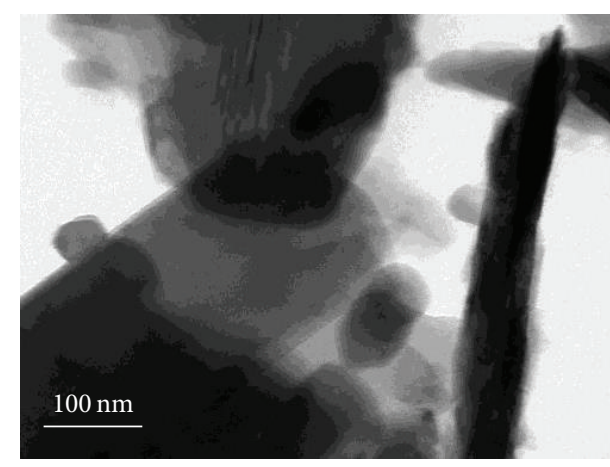

(a)

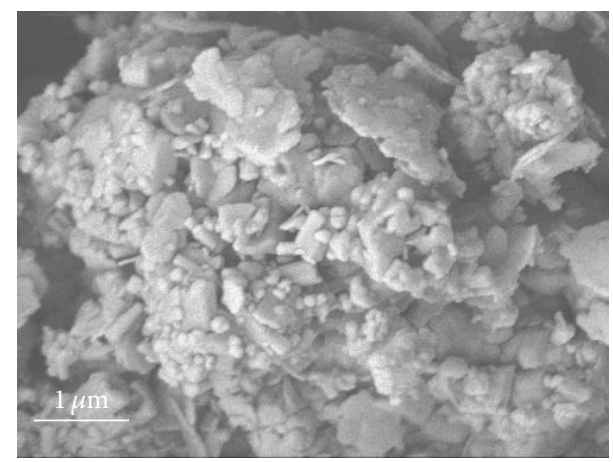

(c)

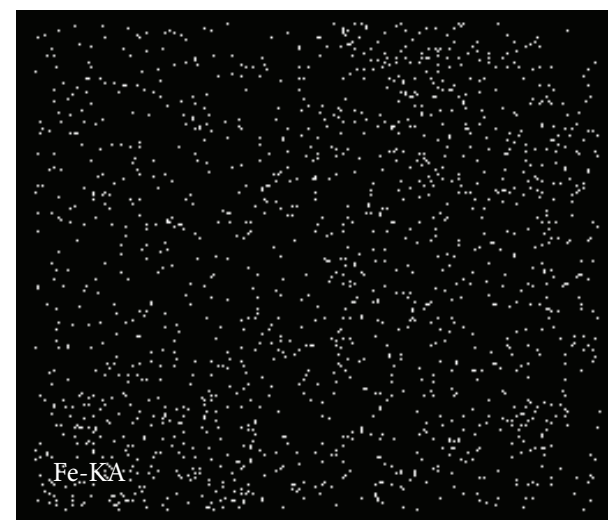

(e)

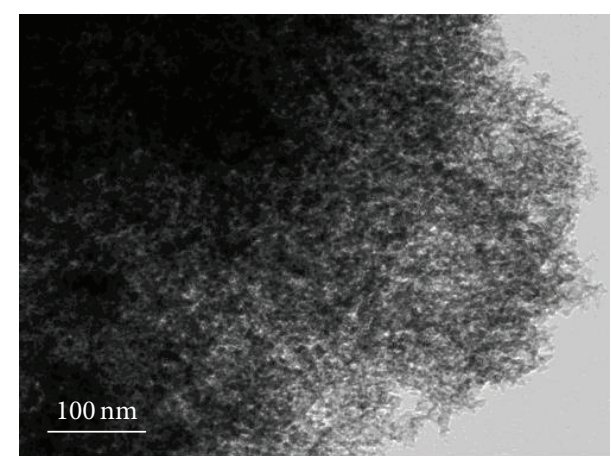

(b)

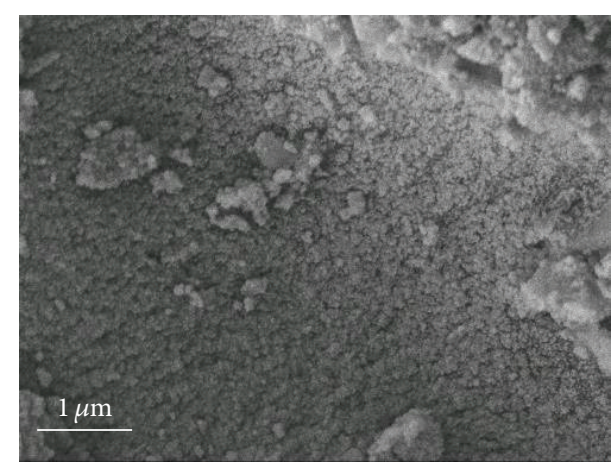

(d)

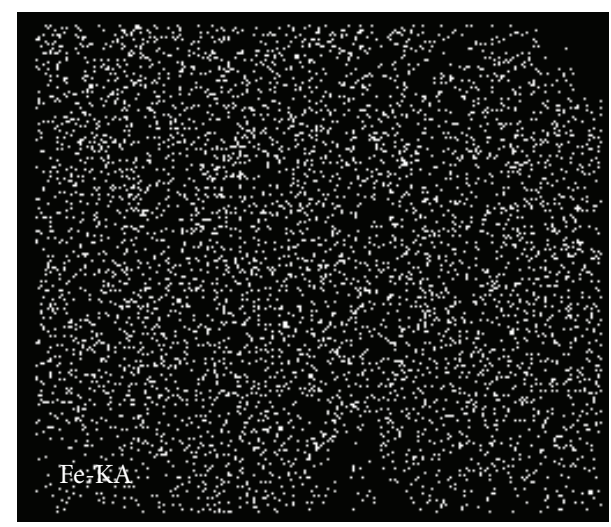

(f)

FIgURE 3: The TEM images of dry RM (a) and MRM (b); SEM images of dry RM (c) and MRM (d); EDX-map (Fe distribution) of RM (e) and MRM (f).

curve (see Figure 4(b)); this characteristic seriously limits the active metal contacting with methane during CMD. The isotherm of MRM can be categorized as classical type IV; the hysteresis loops belong to the $\mathrm{H} 2$ type with steep adsorption and desorption branches, suggesting that MRM possesses a typical mesoporous structure [32]. The pore size of MRM (see Figure 4(b)) was mainly distributed from 3 to $12 \mathrm{~nm}$, which confirms that MRM is a kind of nanomesoporous material. As presented in Table 2, after modification, the specific surface area and total pore volumes of dry RM improve from $8.00 \mathrm{~m}^{2} / \mathrm{g}$ and $0.08 \mathrm{~cm}^{3} / \mathrm{g}$ to $190.61 \mathrm{~m}^{2} / \mathrm{g}$ and $0.39 \mathrm{~cm}^{3} / \mathrm{g}$, respectively, signifying that the textural properties of dry RM have been greatly improved after modification, which is corresponding with the results that Figures 3(a) and 3(b) showed above. We inferred that the enhancement of surface area and pore volumes may be helpful in improving the activity and/or stability of MRM for CMD; therefore, the catalytic performance of catalysts has been tested to confirm this inference.

3.4. Activity of Catalysts in Methane Decomposition. The activity and stability of catalysts (dry RM and MRM) for $\mathrm{CMD}$ at $800^{\circ} \mathrm{C}$ were compared, and the results were showed in Figure 5. Figure 5(a) shows the gas production $\left(\mathrm{H}_{2}\right.$ and $\mathrm{CO})$ volume fraction curves, and Figure 5(b) shows the methane conversion kinetic curves. 


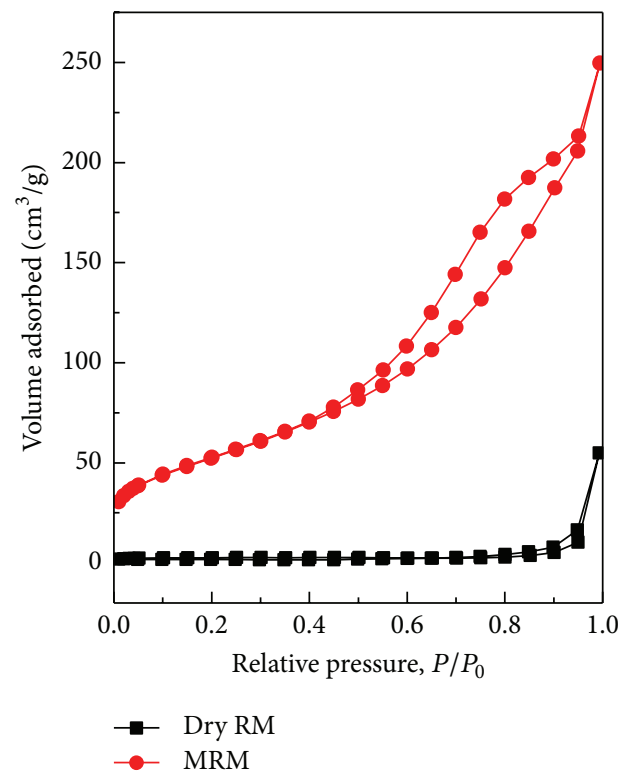

(a)

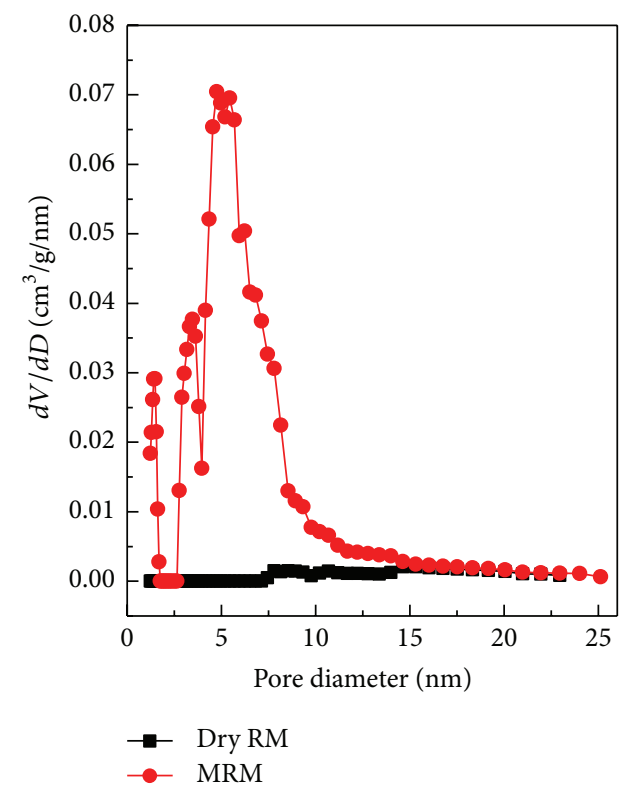

(b)

FIgure 4: The BET analysis of dry RM and MRM.

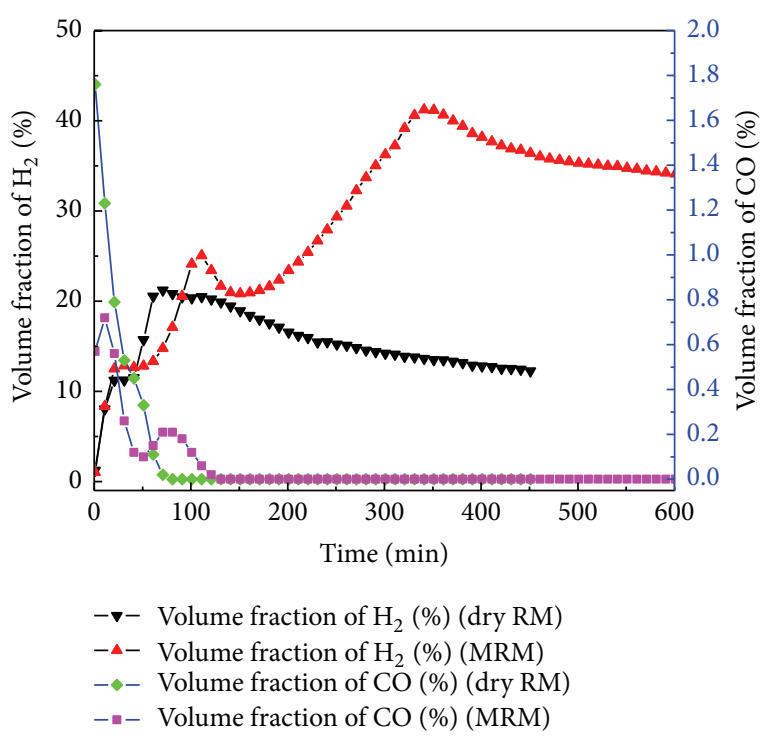

(a)

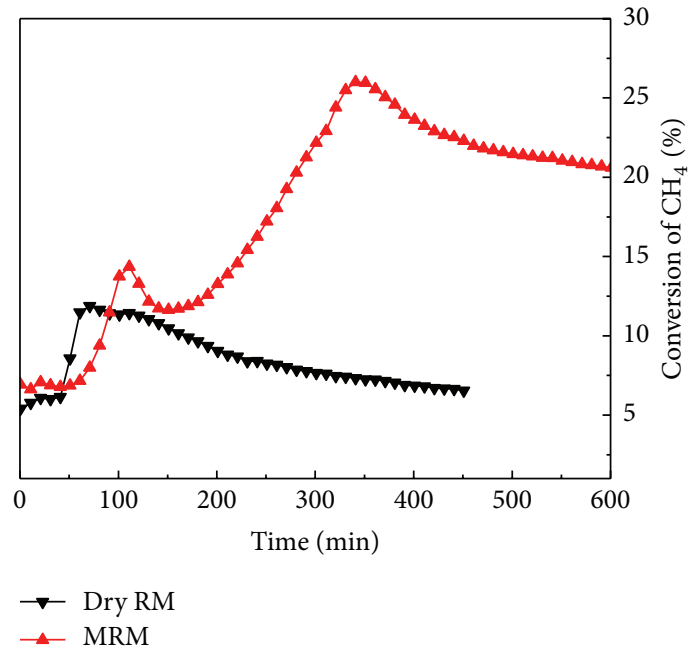

(b)

Figure 5: The gas volume fraction curves (a) and methane conversion curves (b) of the catalysts for CMD at $800^{\circ} \mathrm{C}$.

TABLE 2: The textural properties of dry RM and MRM.

\begin{tabular}{lccc}
\hline Samples & ${\text { Surface } \text { area }^{\mathrm{a}}\left(\mathrm{m}^{2} / \mathrm{g}\right)} V_{\text {tot }}\left(\mathrm{cm}^{3} / \mathrm{g}\right)$ & $D_{\text {DFT-ads }}{ }^{\mathrm{b}}(\mathrm{nm})$ \\
\hline Dry RM & 8.00 & 0.08 & 14.60 \\
MRM & 190.61 & 0.39 & 4.80 \\
\hline
\end{tabular}

${ }^{\mathrm{a}}$ Multipoint BET surface area.

${ }^{b}$ Maximum of DFT pore diameter as determined from the adsorption branch.

In Figure 5(a), we can observe that the initial stage of the reaction will accompany the production of $\mathrm{CO}$ and $\mathrm{H}_{2}$, and $\mathrm{CO}$ is derived from the reduction of $\mathrm{Fe}_{2} \mathrm{O}_{3}$ species in the temperature of $800^{\circ} \mathrm{C}$. The $\mathrm{CO}$ volume fraction curve of dry $\mathrm{RM}$ shows quick declining in the initial reaction; then $\mathrm{CO}$ disappeared after 70 minutes; it can be inferred that, after 70 minutes of the reaction, the exposed $\mathrm{Fe}_{2} \mathrm{O}_{3}$ species have been reduced into metal $\mathrm{Fe}$ by methane. The $\mathrm{CO}$ volume fraction curve of MRM shows two peaks and CO disappeared after 110 minutes of reaction. Because the modification process enhanced the specific surface area and total pore volume of MRM, almost all the $\mathrm{Fe}_{2} \mathrm{O}_{3}$ species in MRM were exposed, so that much higher content of exposed $\mathrm{Fe}_{2} \mathrm{O}_{3}$ species led to much longer reducing time under the same conditions; 
the first peak of $\mathrm{CO}$ volume fraction curve may be due to the reduction of the $\mathrm{Fe}_{2} \mathrm{O}_{3}$ species in external structure of MRM, while the second peak was probably ascribed to the reduction of the $\mathrm{Fe}_{2} \mathrm{O}_{3}$ species in internal structure of MRM. The $\mathrm{H}_{2}$ volume fraction curve of dry RM rises quickly until attaining its maximum (21.21\%) at 70 minutes of the reaction, and then it gradually declines as the reaction continues. An interesting phenomenon that should be paid attention to is that the $\mathrm{H}_{2}$ volume fraction curve of MRM exhibits two peaks; the first peak (25.04\%) appears at 110 minutes of the reaction, which is much later than when dry RM attains its maximum activity. However, 110 minutes later, MRM does not attain its maximum activity; the $\mathrm{H}_{2}$ volume fraction curve shows a decreasing-increasing variation tendency from 110 to 340 minutes. As mentioned above, MRM is assembled by a number of uniformly nanoscale particles and shows abundant wormhole-like pore structure (see Figure 3(b)), even though all the exposed $\mathrm{Fe}_{2} \mathrm{O}_{3}$ species in MRM have been reduced into $\mathrm{Fe}$ after 110 minutes' reaction, but the adsorption of methane molecules on the new generated active center is not yet saturated; meanwhile, the active center in external structure of the catalyst was partly covered by the carbon deposits and deactivated [33]. Therefore, 110 minutes later, the $\mathrm{H}_{2}$ volume fraction curve shows a short time decrease variation tendency; after the following 40 minutes, the methane molecules are continually diffusing into the internal pore structure of MRM and occupying the active center; the $\mathrm{H}_{2}$ volume fraction curve of MRM then shows an increase variation tendency and attains its maximum (41.22\%) at 340 minutes, which may suggest that the adsorption of methane molecules on the active center is saturated at that time; then the $\mathrm{H}_{2}$ volume fraction curve is gradually declining as the reaction continues. The methane conversion curves (see Figure 5(b)) show similar tendency as $\mathrm{H}_{2}$ volume fraction curves; the peak methane conversion of MRM obtained was $25.99 \%$, much higher than those of dry RM (11.88\%); meanwhile, MRM exhibits much higher activity and much longer lifetime than those of dry RM; this behavior suggests that modification process significantly improved the activity and stability of dry RM for CMD.

In order to study the effect of CMD process influencing the morphology and structure of MRM, we utilized SEM to investigate the morphologies of MRM after CMD in our following work.

3.5. The Morphologies of MRM after CMD. The SEM image of MRM after CMD is shown in Figure 6. Compared with Figure 3(d), Figure 6 shows many differences that the carbon deposits covered the surface and embedded into the pore structure of the catalyst, which should result in the deactivation of the catalyst [34]. These carbons can be classified into two types based on their morphologies: spheric-like carbons and filamentous carbons; the amount of spheric-like carbons is far more than that of filamentous carbons. The formation of the spheric-like carbons is ascribed to the iron species covered by graphite layers [9], and this part of iron species that have been covered should be deactivated for methane decomposition, because the iron species can not contact

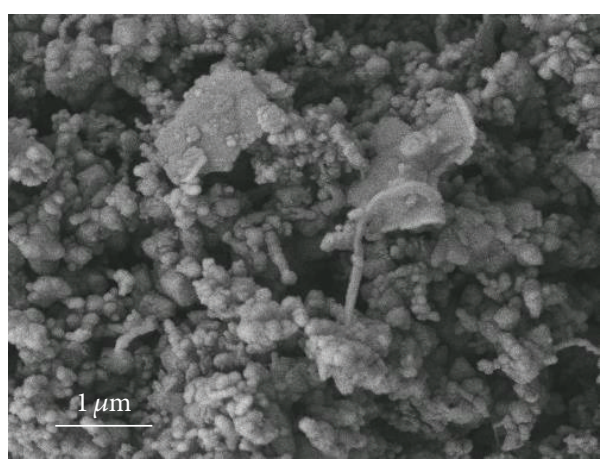

Figure 6: The SEM images of MRM after CMD.

with methane molecules; the filamentous carbons formed on metal catalysts could help the metal remaining exposed and active [6]. Therefore, the deactivation of the catalyst should be attributed to the formation of large amount of spheric-like carbons.

\section{Conclusions}

Red mud (RM), as the industrial wastes, has been utilized to prepare a type of nanomesoporous catalyst through the modification method. After modification, the mineral composition of dry RM changed and almost all of $\mathrm{Na}$ and Ca have been removed; the textural properties of dry RM significantly improved that the specific surface area and total pore volumes improved from $8.00 \mathrm{~m}^{2} / \mathrm{g}$ and $0.08 \mathrm{~cm}^{3} / \mathrm{g}$ to $190.61 \mathrm{~m}^{2} / \mathrm{g}$ and $0.39 \mathrm{~cm}^{3} / \mathrm{g}$, respectively; the structure of dry RM transformed into an abundant wormhole-like pore structure assembled by a number of uniformly nanoscale particles; the pore size distributions of modified red mud (MRM) were mainly ranged from 3 to $12 \mathrm{~nm}$. The activity and stability of MRM were much better than those of dry RM for CMD; the peak methane conversion obtained by MRM was $25.99 \%$, much higher than that of dry RM obtained (11.88\%) in the same condition.

\section{Competing Interests}

The authors declare that they have no competing interests.

\section{Acknowledgments}

This work was supported by the "Strategic Priority Research Program Climate Change: Carbon Budget and Related Issues" of the Chinese Academy of Sciences (Grant no. XDA05010300).

\section{References}

[1] Y. Yang, F. Zhang, H. Wang, Q. Yao, X. Chen, and Z.-H. $\mathrm{Lu}$, "Catalytic hydrolysis of ammonia borane by cobalt nickel nanoparticles supported on reduced graphene oxide for hydrogen generation," Journal of Nanomaterials, vol. 2014, Article ID 294350, 9 pages, 2014. 
[2] K. D. Dewoolkar and P. D. Vaidya, "Improved hydrogen production by sorption-enhanced steam methane reforming over hydrotalcite- and calcium-based hybrid materials," Energy \& Fuels, vol. 29, no. 6, pp. 3870-3878, 2015.

[3] A. J. De Abreu, A. F. Lucrédio, and E. M. Assaf, "Ni catalyst on mixed support of $\mathrm{CeO}_{2}-\mathrm{ZrO}_{2}$ and $\mathrm{Al}_{2} \mathrm{O}_{3}$ : effect of composition of $\mathrm{CeO}_{2}-\mathrm{ZrO}_{2}$ solid solution on the methane steam reforming reaction," Fuel Processing Technology, vol. 102, pp. 140-145, 2012.

[4] S. He, L. Zhang, S. He et al., " $\mathrm{Ni} / \mathrm{SiO}_{2}$ catalyst prepared with nickel nitrate precursor for combination of $\mathrm{CO}_{2}$ reforming and partial oxidation of methane: characterization and deactivation mechanism investigation," Journal of Nanomaterials, vol. 2015, Article ID 659402, 8 pages, 2015.

[5] X. Yin, L. Hong, and Z. Gong, "A decrease in $\mathrm{NiO}-\mathrm{MgO}$ phase through its solid solution equilibrium with tetragonal $\left(\mathrm{La}_{1-z} \mathrm{Sr}_{z}\right)_{2} \mathrm{Ni}_{1-y} \mathrm{Mg}_{y} \mathrm{O}_{4-\delta}$ : effect on catalytic partial oxidation of methane," Journal of Nanomaterials, vol. 2012, Article ID 263568, 10 pages, 2012.

[6] M. Szymańska, A. Malaika, P. Rechnia, A. Miklaszewska, and M. Kozłowski, "Metal/activated carbon systems as catalysts of methane decomposition reaction," Catalysis Today, vol. 249, pp. 94-102, 2015.

[7] A. A. Ibrahim, A. H. Fakeeha, A. S. Al-Fatesh, A. E. Abasaeed, and W. U. Khan, "Methane decomposition over iron catalyst for hydrogen production," International Journal of Hydrogen Energy, vol. 40, no. 24, pp. 7593-7600, 2015.

[8] J. L. Pinilla, R. Utrilla, R. K. Karn et al., "High temperature iron-based catalysts for hydrogen and nanostructured carbon production by methane decomposition," International Journal of Hydrogen Energy, vol. 36, no. 13, pp. 7832-7843, 2011.

[9] S. Takenaka, M. Serizawa, and K. Otsuka, "Formation of filamentous carbons over supported Fe catalysts through methane decomposition," Journal of Catalysis, vol. 222, no. 2, pp. 520-531, 2004.

[10] A. E. Awadallah, A. A. Aboul-Enein, and A. K. Aboul-Gheit, "Impact of group VI metals addition to $\mathrm{Co} / \mathrm{MgO}$ catalyst for non-oxidative decomposition of methane into COx-free hydrogen and carbon nanotubes," Fuel, vol. 129, pp. 27-36, 2014.

[11] S. Takenaka, E. Kato, Y. Tomikubo, and K. Otsuka, "Structural change of Ni species during the methane decomposition and the subsequent gasification of deposited carbon with $\mathrm{CO} 2$ over supported Ni catalysts," Journal of Catalysis, vol. 219, no. 1, pp. 176-185, 2003.

[12] W. Wang, H. Wang, Y. Yang, and S. Jiang, "Ni-SiO 2 and Ni$\mathrm{Fe}-\mathrm{SiO}_{2}$ catalysts for methane decomposition to prepare hydrogen and carbon filaments," International Journal of Hydrogen Energy, vol. 37, no. 11, pp. 9058-9066, 2012.

[13] J. Zhang, L. Jin, Y. Li, and H. Hu, "Ni doped carbons for hydrogen production by catalytic methane decomposition," International Journal of Hydrogen Energy, vol. 38, no. 10, pp. 3937-3947, 2013.

[14] L. Jin, H. Si, J. Zhang et al., "Preparation of activated carbon supported $\mathrm{Fe}-\mathrm{Al}_{2} \mathrm{O}_{3}$ catalyst and its application for hydrogen production by catalytic methane decomposition," International Journal of Hydrogen Energy, vol. 38, no. 25, pp. 10373-10380, 2013.

[15] K. Otsuka, H. Ogihara, and S. Takenaka, "Decomposition of methane over Ni catalysts supported on carbon fibers formed from different hydrocarbons," Carbon, vol. 41, no. 2, pp. 223233, 2003.

[16] Y. Shen and A. C. Lua, "Synthesis of Ni and Ni-Cu supported on carbon nanotubes for hydrogen and carbon production by catalytic decomposition of methane," Applied Catalysis B: Environmental, vol. 164, pp. 61-69, 2015.

[17] S. Takenaka, H. Ogihara, I. Yamanaka, and K. Otsuka, "Decomposition of methane over supported-Ni catalysts: effects of the supports on the catalytic lifetime," Applied Catalysis A: General, vol. 217, no. 1-2, pp. 101-110, 2001.

[18] Q. Liu, R. Xin, and C. Li, "Application of red mud as a basic catalyst for biodiesel production," Journal of Environmental Sciences-China, vol. 25, no. 4, pp. 823-829, 2013.

[19] S. Sushil and V. S. Batra, "Catalytic applications of red mud, an aluminium industry waste: a review," Applied Catalysis B: Environmental, vol. 81, no. 1-2, pp. 64-77, 2008.

[20] J. Alvarez, R. Rosal, H. Sastre, and F. V. Díez, “Characterization and deactivation studies of an activated sulfided red mud used as hydrogenation catalyst," Applied Catalysis A: General, vol. 167, no. 2, pp. 215-223, 1998.

[21] J. Halász, M. Hodos, I. Hannus, G. Tasi, and I. Kiricsi, "Catalytic detoxification of C2-chlorohydrocarbons over iron-containing oxide and zeolite catalysts," Colloids and Surfaces A: Physicochemical and Engineering Aspects, vol. 265, no. 1-3, pp. 171-177, 2005.

[22] S. Sushil and V. S. Batra, "Modification of red mud by acid treatment and its application for CO removal," Journal of Hazardous Materials, vol. 203-204, pp. 264-273, 2012.

[23] J. R. Paredes, S. Ordóñez, A. Vega, and F. V. Díez, "Catalytic combustion of methane over red mud-based catalysts," Applied Catalysis B: Environmental, vol. 47, no. 1, pp. 37-45, 2004.

[24] M. Balakrishnan, V. S. Batra, J. S. J. Hargreaves et al., "Hydrogen production from methane in the presence of red mud-making mud magnetic," Green Chemistry, vol. 11, no. 1, pp. 42-47, 2009.

[25] S. C. Kim, S. W. Nahm, and Y.-K. Park, "Property and performance of red mud-based catalysts for the complete oxidation of volatile organic compounds," Journal of Hazardous Materials, vol. 300, pp. 104-113, 2015.

[26] J. L. Pinilla, R. Utrilla, M. J. Lázaro, R. Moliner, I. Suelves, and A. B. García, "Ni- and Fe-based catalysts for hydrogen and carbon nanofilament production by catalytic decomposition of methane in a rotary bed reactor," Fuel Processing Technology, vol. 92, no. 8, pp. 1480-1488, 2011.

[27] S. Sushil, A. M. Alabdulrahman, M. Balakrishnan et al., "Carbon deposition and phase transformations in red mud on exposure to methane," Journal of Hazardous Materials, vol. 180, no. 1-3, pp. 409-418, 2010.

[28] A. Alp and M. S. Goral, "The influence of soda additive on the thermal properties of red mud," Journal of Thermal Analysis and Calorimetry, vol. 73, no. 1, pp. 201-207, 2003.

[29] A. Atasoy, "An investigation on characterization and thermal analysis of the Aughinish red mud," Journal of Thermal Analysis and Calorimetry, vol. 81, no. 2, pp. 357-361, 2005.

[30] H. Nath, P. Sahoo, and A. Sahoo, "Characterization of Red Mud treated under high temperature fluidization," Powder Technology, vol. 269, pp. 233-239, 2015.

[31] M. L. P. Antunes, S. J. Couperthwaite, F. T. Da Conceição et al., "Red mud from Brazil: thermal behavior and physical properties," Industrial and Engineering Chemistry Research, vol. 51, no. 2, pp. 775-779, 2012.

[32] H. G. El-Shobaky and M. M. Mokhtar, "Effect of $\mathrm{Li}_{2} \mathrm{O}$ and $\mathrm{CoO}$-doping of $\mathrm{CuO} / \mathrm{Fe}_{2} \mathrm{O}_{3}$ system on its surface and catalytic properties," Applied Surface Science, vol. 253, no. 24, pp. 94079413, 2007. 
[33] M. A. Ermakova, D. Y. Ermakov, and G. G. Kuvshinov, "Effective catalysts for direct cracking of methane to produce hydrogen and filamentous carbon. Part I. Nickel catalysts," Applied Catalysis A: General, vol. 201, no. 1, pp. 61-70, 2000.

[34] X. Li, G. Zhu, S. Qi, J. Huang, and B. Yang, "Simultaneous production of hythane and carbon nanotubes via catalytic decomposition of methane with catalysts dispersed on porous supports," Applied Energy, vol. 130, pp. 846-852, 2014. 

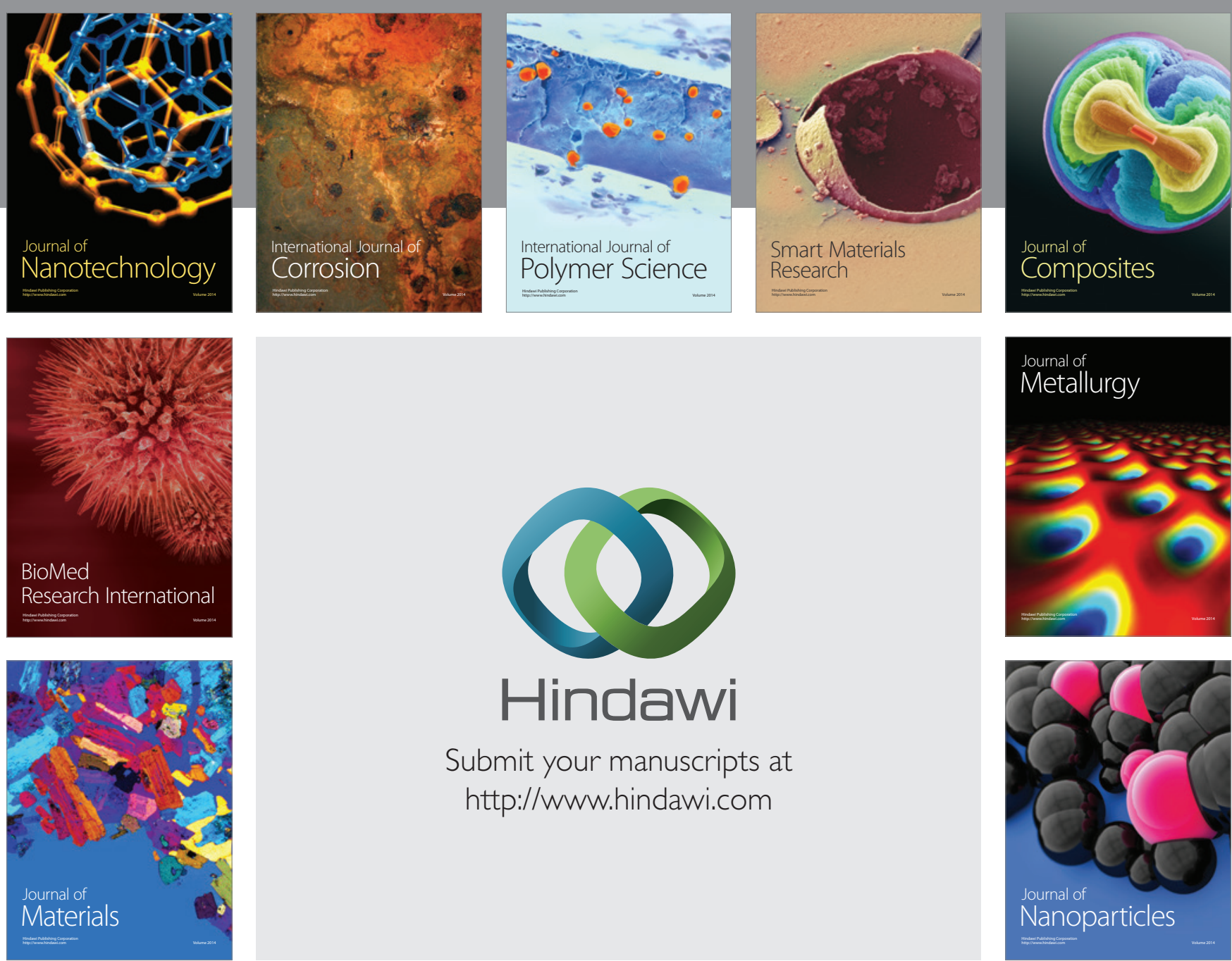

\section{Hindawi}

Submit your manuscripts at

http://www.hindawi.com

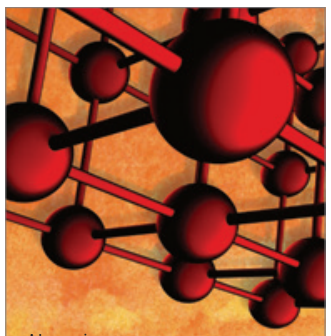

Materials Science and Engineering
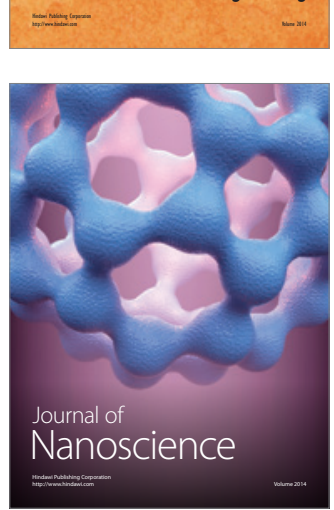
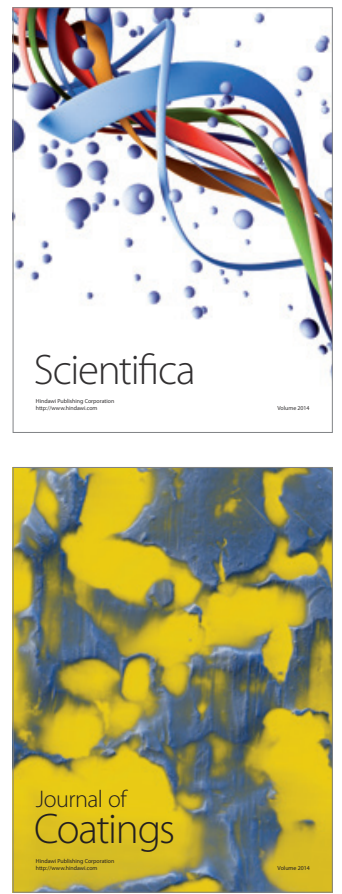
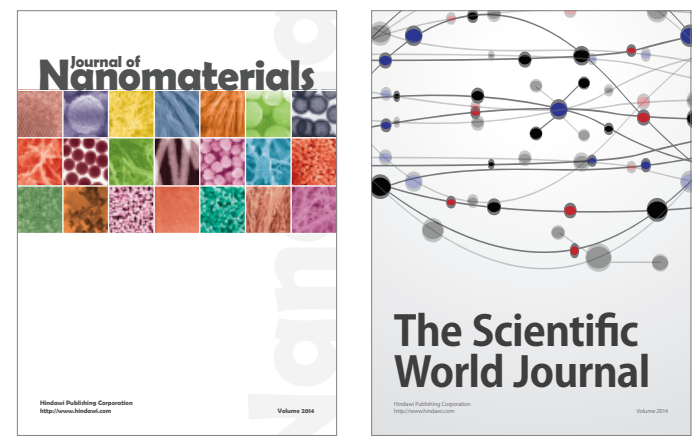

The Scientific World Journal
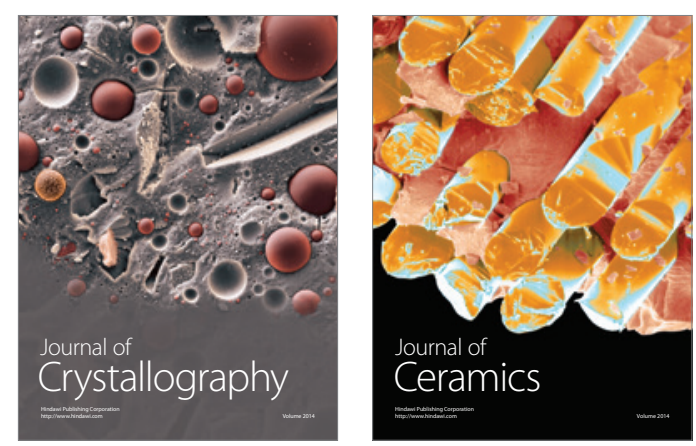
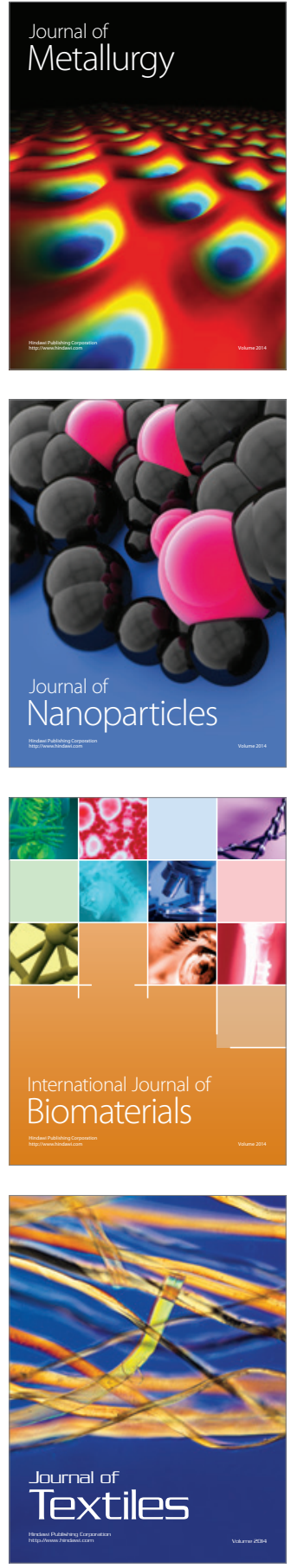